DOI: $10.17805 /$ zpu.2018.3.14

\title{
Социокультурные детерминанты этнонациональной политики (на примере Новосибирска)
}

\author{
О. А. ПЕРСИДСКАЯ
}

ИНСТИТУТ ФИЛОСОФИИ И ПРАВА СИБИРСКОГО ОТДЕЛЕНИЯ РОССИЙСКОЙ АКАДЕМИИ НАУК

В статье анализируется межэтническая ситуация и состояние межэтнических отношений в городе Новосибирске. Население города представляется как межэтническое сообщество - целостный социокультурный объект, элементы которого (этнические группы) одновременно интегрированы в сообщество, но сохраняют свою этнокультурную отличительность. Целью статьи является выделение комплекса социокультурных детерминант значимых для сообщества факторов этносоциальной жизни, которые задают направление развития межэтнического сообщества. Отмечено, что, так как эти детерминанты оказывают значимое влияние на гармоничность межэтнических отношений в пространстве города, их выявление и анализ имеют особое значение для этнонациональной политики муниципального уровня.

Проанализированы результаты экспертного опроса, проведенного в Новосибирске в 2016-2017 гг. К социокультурным детерминантам отнесены, во-первых, сложности социально-экономического плана, которые формируют чувство незащищенности у принимающего сообщества и снижают уровень его толерантности к иноэтничным мигрантам. Во-вторых, анклавизационный процесс, который исключает места компактного расселения мигрантов из системы социально-культурного обмена. В-третьих, в качестве детерминанты, ставшей причиной ряда проблем в области межэтнических отношений, рассмотрена ограниченная эффективность мер, принимаемых административными структурами города для налаживания коммуникации между принимающим населением и диаспорами. Проведенный анализ позволил заключить, что для гармонизации межэтнических отношений в городе следует повышать общий уровень благосостояния населения, наблюдать за изменениями в этнотерриторальной структуре города и искать принципиально новые механизмы коммуникации принимающего населения и мигрантов. Акцентировано, что для повышения своей эффективности муниципальная этнонациональная политика должна рассматривать в качестве объекта межэтническое сообщество в целом и учитывать широкий комплекс социокультурных детерминант, влияющих на его развитие. 
Ключевые слова: социокультурные детерминанты; межэтническое сообщество; муниципальная этнонациональная политика; Новосибирск; миграция; анклавизационный процесс; диаспора; социальное самочувствие

\section{BВЕАЕНИЕ}

Понимание закономерностей развития социальных систем невозможно без знания основных детерминант (здесь - факторов, причин, обусловливающих то или иное явление), которые его направляют. В рамках неклассического подхода к определению сути социальной детерминации понятие об обществе строится на основе не механических, а системных, органических типах причинности. В этой связи происходит отказ от жесткого детерминизма, а акцент переносится на сложный, многосоставный характер детерминации социальных систем, который позволяет учесть более широкий контекст функциональных взаимосвязей.

Существует ряд подходов к определению сути социальной детерминации: синергетический, модернизационный, конфликтологический, структурно-функциональный и др. (Волков, 2004: 12-14), но для нас интерес представляет социокультурный подход, теоретические основы которого были раскрыты П. А. Сорокиным в его концепции социокультурной динамики (Сорокин, 2000). Согласимся с М. А. Абрамовой и В. Г. Костюком, что «среди множества детерминант... трансформации российского общества и его сообществ... социокультурные, понимаемые как интегральное единство их социальных, культурных и личностных аспектов (детерминант), являются наиболее значимыми, т. к. трансформируют всю социальную систему (или ее подсистему)» (Абрамова, Костюк, 2018: 87). Выявление социокультурных детерминант предполагает комплексный анализ влияния социальных, культурных, экономических, демографических и политических процессов на сообщество.

В традиции устоявшихся теоретико-методологических подходов новосибирской этносоциологической школы (Костюк, Персидская, 2007) в качестве объекта детерминации рассматривается межэтническое сообщество - специфическая форма социокультурной интеграции локального общества. Согласно выводам В. В. Мархинина и И.В. Удаловой, основных разработчиков концепта межэтнического сообщества, оно складывается на уровне регионов Российской Федерации в процессе долгой истории совместного проживания разных этнических групп под воздействием «замиряющей» силы присутствия русского этноса (Мархинин, Удалова, 2014: 76). Такое сообщество характеризуется коммунальностью, доходящей до содружества (Абрамова, Гончарова, Костюк, 2017: 150), благодаря тому, что у взаимодействующих этнических групп вырабатываются определенные стабильные практики бесконфликтных межэтнических взаимодействий. Межэтническое сообщество отличает особый вид общности этнических групп: они разделяют цели совместного развития и соединены культурно-ценностными узами. При этом каждая из этнических групп в рамках межэтнического сообщества сохраняет собственную этнокультурную отличительность, а их взаимодействие обеспечивает многоаспектное развитие всего сообщества.

Представляется, что анализ особенностей социокультурной детерминации локальных межэтнических сообществ значим как для понимания долгосрочных тенденций развития таких сообществ, так и для комплексного описания текущих проблем межэтнических отношений. Такой анализ является более широким по сравнению с точечным анализом проблем в отношениях между представителями разных национальностей и позволяет системно взглянуть на все сообщество в единстве составляющих 
его элементов (этнических групп). Целью данной статьи является анализ межэтнического сообщества Новосибирска с выделением тех детерминант его развития, которые оказывают наиболее сильное влияние на межэтническую ситуацию в городе. Подчеркнем, что особую значимость, по нашему мнению, такой анализ представляет для гармонизации межэтнических отношений в практике административного управления.

\section{МЕЖЭТНИЧЕСКОЕ СООБЩЕСТВО НОВОСИБИРСКА}

Современные крупные города, имеющие сложившийся этнокультурный облик, тоже могут рассматриваться в качестве межэтнических сообществ, но не регионального, а муниципального уровня. Миграционные процессы последних лет являются существенным вызовом для устоявшейся структуры межэтнических сообществ городов. Недостаточно ограничиваться заключением, что миграция изменяет лишь распределение долей разноэтнического населения в городе; важно, что она вызывает качественные трансформации межэтнического сообщества на уровне структурнофункциональной организации и социально-антропологических характеристик. Согласимся с Ю. В. Поковым и Е. А. Тюгашевым, что, хотя «город осуществляет отбор мигрантов, адаптивных к его условиям и вписывающихся в городское сообщество», тем самым проявляя себя как интегрированное целое - межэтническое сообщество, все же «изменение этносоциального состава населения влечет за собой реорганизацию межэтнических отношений в городском сообществе и его социокультурную трансформацию, которая не всегда происходит гладко и безболезненно» (Попков, Тюгашев, 2017: 9).

Новосибирск - один из крупнейших городов Российской Федерации. Численность его населения на начало 2018 г. - 1 млн 600 тыс. человек. Отметим, что, так как город изначально формировался как населенный пункт с разноэтническим составом населения (при значительном преобладании русских), в массовом сознании жителей города установка на интернационализм как основу межнациональных отношений до сих пор имеет значительный вес. Так, по результатам массового опроса 2014 г., проведенного сотрудниками Института философии и права СО РАН при участии автора (руководитель - А-р филос. наук, проф. Ю. В. Попков), 64\% опрошенных новосибирцев согласились с утверждением «В Новосибирске представители разных народов мирно уживаются» (Этносоциальные процессы ..., 2015: 166). В то же время в последние десятилетия этнические пропорции в городе существенно изменяются под воздействием миграционных процессов. Так, на фоне снижения численности наиболее многочисленных, помимо русских, традиционных для Новосибирска этнических групп - украинцев, татар, чувашей, немцев, белорусов - происходит увеличение численности представителей народов Средней Азии и Кавказа.

В этой связи особо значимой задачей для муниципального управления видится анализ напряженности межэтнических взаимоотношений в пространстве города. По результатам массового опроса 2014 г. видно, что межнациональные отношения в городе оцениваются опрошенными жителями скорее как терпимые, чем хорошие (там же: 155). На фоне усиления миграционных процессов респонденты ожидают дальнейшего роста напряженности этих отношений. Почти половина всех респондентов допускают возможность конфликтов на национальной почве. Главными локальными проблемными зонами, которые могут стать или уже стали очагами межнациональной напряженности, по мнению опрошенных, являются места концентрации людей 
по этническому принципу. Напряженность в основном касается отношений местного населения и мигрантов, прежде всего - выходцев из регионов Кавказа и Средней Азии. При этом этнические группы, чей основной приток в город пришелся на конец 1990-х годов, например азербайджанцы, вызывают у местных жителей меньше негативных нареканий. Как нам кажется, это свидетельствует о наличии определенного периода, требующегося для адаптации межэтнического сообщества к ранее незнакомым әтническим группам.

Так как увеличение численности населения Новосибирска всегда происходило не только за счет естественного прироста, но в значительной степени за счет миграции иноэтничного населения, практики воспроизводства этничности, идентификационные установки у представителей разных әтнических групп, населяющих город, а также стандарты общественных отношений формируются на основе сложного поликультурного взаимодействия. Характеризуя отличительность межэтнического сообщества Новосибирска от других крупных российских городов, подчеркнем значительную этническую дробность населения города (при сохраняющемся доминировании русских), которая приводит к выраженной вариативности этнокультурных, лингвистических, этноэкономических, этноконфессиональных и этнодемографических укладов, складывающихся в сложную мозаику (см.: Антропов, 2013; Ушаков, 2013).

\section{РЕААИЗАЦИЯ ЭТНОНАЦИОНААЬНОЙ ПОАИТИКИ \\ НА ФЕАЕРААЬНОМ И МУНИЦИПААЬНОМ УРОВНЯХ}

Регулирование сферы межэтнических отношений осуществляется в деятельности органов государственной власти и местного самоуправления, относящейся к области этнонациональной политики. Основные концептуальные установки и ориентиры этой политики закреплены в Стратегии государственной национальной политики Российской Федерации на период до 2025 (принята в 2012 г.). Свою практическую реализацию они получили в утвержденной в 2013 г. Федеральной целевой программе «Укрепление единства российской нации и этнокультурное развитие народов России (2014-2020 годы)». Аля выработки и реализации государственной национальной политики в 2015 г. было создано Федеральное агентство по делам национальностей.

Положительно оценивая действия федеральной власти в вопросе регулирования межнациональных отношений, отметим значимую структурную проблему, осложняющую реализацию этнонациональной политики на уровне муниципалитетов. В соответствии с Федеральным законом от 6 октября 1999 г. № 184-Ф3 «Об общих принципах организации законодательных (представительных) и исполнительных органов государственной власти субъектов Российской Федерации» муниципальные органы управления несут ответственность за состояние межэтнических отношений, решение проблем и урегулирование конфликтов в этой сфере. В то же время они практически не наделены возможностями для полноценной реализации своих полномочий и ответственности. Согласимся с Ю. В. Попковым, что «в федеральном законодательстве до сих пор в должной мере не урегулирован вопрос, касающийся роли и возможностей органов местного самоуправления в решении задач национальной политики, форм и методов работы, механизма и объемов финансирования, соответствующих характеру и остроте реальных проблем в данной сфере» (Этносоциальные процессы ... , 2015: 61). В этой сложной ситуации органы власти муниципалитетов вынуждены искать способы гармонизации межэтнических отношений, которые, с одной стороны, не вступали бы в противоречие с федеральным законодательством, а с дру- 
гой - позволили бы держать область межэтнических отношений под контролем, учитывая уникальную специфику межэтнического сообщества в конкретном населенном пункте.

К основным документам, регулирующим область этнонациональной политики в Новосибирске, можно отнести Концепцию реализации национальной политики в городе Новосибирске, утвержденную в 2013 г. на заседании особого коллегиального совещательного органа при мэрии города - Консультативного совета по вопросам этнокультурного развития и межнациональных отношений (далее - Совета) (Концепция реализации ... : Электронный ресурс). В состав Совета вошли сотрудники мэрии города, руководители общественных и национально-культурных организаций, представители научного сообщества и религиозных объединений; председательствует в Совете мәр города. На основе Концепции разработан и утвержден Комплексный план мероприятий, направленных на гармонизацию межнациональных и межконфессиональных отношений на территории города Новосибирска, на 2017-2020 годы (О комплексном плане ... : Электронный ресурс). Так как в Стратегии государственной национальной политики Российской Федерации прямо не предусмотрено возможности разработки муниципальных концепций реализации национальной политики, при утверждении новосибирской Концепции пришлось пойти на компромисс: она утверждена Советом, а не законодательными и исполнительными органами местного самоуправления (Этносоциальные процессы ..., 2014: 141). Хотя это, возможно, и снижает ее статус, но, несомненно, не отменяет ее значимой роли по повышению эффективности принимаемых в области национальной политики города решений, гибко адаптированных под локальные особенности межэтнического сообщества Новосибирска.

\section{СОЦИОКУАЬТУРНЫЕ АЕТЕРМИНАНТЫ}

\section{МЕЖЭТНИЧЕСКОГО СООБЩЕСТВА НОВОСИБИРСКА: НОВЫЕ ВЫЗОВЫ}

Социокультурная жизнь межэтнического сообщества города находится в непрерывном развитии, изменения среды формируют новые социокультурные детерминанты. Эти детерминанты указывают на актуальные проблемы развития сообщества в тех областях социальной жизни, которые именно в данный момент определяют межэтническую ситуацию в целом. Поэтому для практики административного управления детерминанты развития межэтнического сообщества могут быть переосмыслены как детерминанты этнонациональной политики. Учет социокультурных детерминант в административном управлении, как представляется, может улучшить адаптацию принимаемых муниципальным правительством мер к локальной ситуации. Аиагностика состояния разных сторон межэтнических отношений может быть осуществлена на основе выводов этносоциологических исследований. Представляется, что наибольший эффект дает, во-первых, заданная периодичность таких исследований, которая позволяет выявить долгосрочные динамические тренды, а во-вторых, сочетание разных методов: массовых и экспертных опросов, наблюдения, фокус-групп.

В данной работе выявление и описание социокультурных детерминант, существенно влияющих, на наш взгляд, на межэтническое сообщество Новосибирска, но пока не нашедших отражения в текущем курсе этнонациональной политики, сделано на основе анализа результатов экспертного опроса, проведенного в Новосибирске в 2016-2017 гг. сотрудниками Института философии и права СО РАН и Новосибирского государственного технического университета (подробнее см.: Попков, Костюк, 
2017; Персидская, 2017а). К участию в исследовании были привлечены три группы экспертов, соприкасающиеся с темой межэтнических отношений в Новосибирске: работники вузов и научных институтов, имеющие опыт исследований межэтнических отношений, специалисты администраций и культурных учреждений города, сталкивающиеся с этнической тематикой в своей работе, авторитетные представители диаспор и организаций гражданского общества.

Как показали выводы исследования, одной из значимых детерминант формирования межэтнической напряженности экспертами названы сложности социальноэкономического плана. Напряженный социальный фон, сформированный экономическими трудностями, нестабильной политической ситуацией, снижением уровня благополучия населения, находит выход накопившейся негативной энергии в области межэтнических отношений. В этой связи, хотя суть существующей межэтнической напряженности составляет целый комплекс социально-экономических проблем, она часто объясняется косвенной причиной - мигрантами (подробнее см.: Персидская, Попков, Скалабан, 2016). Проблема адаптации местного населения к изменяющейся в результате активных миграционных процессов этносоциальной ситуации, которая формирует устойчивое чувство незащищенности принимающего сообщества и, как следствие, его низкий уровень толерантности, стоит особенно остро.

Аругая детерминанта имеет отношение к изменениям в территориально-этнической структуре городского сообщества: экспертами было зафиксировано появление на карте Новосибирска мест концентрации этнических мигрантов в виде анклавоподобных поселений (подробнее см: Madiukova, Persidskaia, 2017). Эти территории воспринимаются принимающим сообществом как выбивающиеся из общей этнической картины города и потенциально конфликтогенные. В местах компактного расселения мигрантов - как в многоквартирных домах, так и на территории частного сектора местных жителей тревожит угроза собственной безопасности, «замусоренность» территорий, низкий уровень культуры поведения мигрантов, плохое знание ими русского языка. Характеризуя такие территории, эксперты отмечали, что, с точки зрения принимающего сообщества, объединение социально-культурной системы анклавоподобного поселения с сетью города отсутствует. Это означает, что мигранты, населяющие их, адаптированы (имеют работу, жилье, потребляют бюджетные ресурсы города - в частности, социальные услуги, пособия и выплаты), но при этом исключены из области культурно-ценностного обмена. Аанные анклавоподобные поселения в значительной мере закрыты от стороннего наблюдателя, поэтому служат источником формирования самых разных представлений о себе, в том числе пугающего принимающее сообщество характера.

Еще одна значимая детерминанта, ставшая причиной целого ряда проблем в области межэтнических отношений, связана с ограниченной эффективностью мер, принимаемых административными структурами города для налаживания коммуникации между принимающим населением и мигрантами. Увеличение числа мигрантов в Новосибирске, как и в других крупных городах, привело к формированию в пространстве города ряда устойчивых этнокультурных образований в виде диаспор, однако контакты диаспор и принимающего сообщества ограничены и поверхностны (подробнее: Персидская, 2017b). Как считают эксперты, рядовой горожанин сталкивается с диаспорами лишь на городских праздниках и фестивалях, где в игровой, привлекательной форме представляются обычаи, традиции и фольклор этнических групп, и, возможно, заочно знаком с некоторыми главами диаспор, которые являются медийными лицами, 
близкими к муниципальным властям. Однако такой способ интеграции новых этнических групп в межэтническое сообщество, как представляется, не работает. «Фестивальное» взаимодействие приводит к искаженному пониманию картины мира и системы ценностей другой культуры, замене ее на упрощенный, схематический эрзац; соответственно, взаимопонимание и взаимопроникновение культур становится в таких условиях практически невозможным.

\section{ЗАКАЮЧЕНИЕ}

Рассмотренные детерминанты, оказывающие, на наш взгляд, существенное влияние на межэтническое сообщество Новосибирска: усложнение социально-экономической ситуации, анклавизационный процесс, эрзатизация образов диаспор - могут влиять на обострение межэтнической ситуации в городе. Представляется, что в этих условиях стратегической задачей органов управления должны выступать повышение общего уровня благосостояния населения города и обеспечение его благоприятного социального самочувствия, внимательное наблюдение за изменениями в этнотерриторальной структуре города и поиск принципиально новых механизмов коммуникации принимающего населения и мигрантов.

В целом подчеркнем, что муниципальная этнонациональная политика должна рассматривать в качестве своего объекта не только острые моменты, требующие быстрого реагирования, - межэтническую напряженность или конфликты, как это прописано в констатирующей части Стратегии государственной национальной политики Российской Федерации. В поле зрения этой политики должно находиться межэтническое сообщество в целом (Попков, 2017: 124): его этнопрофессиональная и этнотерриториальная структуры, особенности организации этнических элит, а также такие явления, как пробуждение и всплеск этнического и национального самосознания, рост инициативности этнически ориентированного актива, динамика численного соотношения, статуса и взаимного влияния этнических групп и др. Такой - качественно более широкий - взгляд позволяет определить и зафиксировать социокультурные детерминанты, существенно влияющие на состояние межэтнического сообщества города, но не учтенные в текущем курсе муниципальной этнонациональной политики, и, не дожидаясь эскалации напряжения межэтнических отношений, точечно решать назревающие проблемы.

\section{СПИСОК АИТЕРАТУРЫ}

Абрамова, М. А., Гончарова, Г. С., Костюк, В. Г. (2017) Основные факторы интеграции межэтнических сообществ России // Сибирский философский журнал. Т. 15. № 1. С. 149-158.

Абрамова, М. А., Костюк, В. Г. (2018) Социокультурные детерминанты развития и трансформации общества и сообществ России: исследовательские подходы // Сибирский философский журнал. № 2. С. 86-95.

Антропов, Е. В. (2013) Новосибирск: этнические аспекты возникновения и развития города (конец XIX - начало XXI в.) : автореф. Аис. ... канд. истор. наук. Томск. 17 с.

Волков, С. Г. (2004) Аетерминизм в социокультурном развитии (философско-методологический анализ) : автореф. дис. ... канд. филос. наук. Тула. 19 с.

Концепция реализации национальной политики в городе Новосибирске [Электронный ресурс] // Управление общественных связей мәрии Новосибирска. URL: http://www.uos.novosibirsk.ru/assets/files/documents/municipal/koncepciya-nac-polit.pdf (дата обращения: 01.05.2018).

Костюк, В. Г., Персидская, О. А. (2007) Новосибирская школа этносоциологии: этапы становления, основные результаты // Гуманитарные науки в Сибири. № 1. С. 14-18. 
Мархинин, В. В., Удалова, И. В. (2014) Межэтническое сообщество как социокультурный концепт (постановка проблемы) // Вестник Новосибирского государственного университета. Серия: Философия. Т. 12. Вып. 1. С. 70-78.

О комплексном плане мероприятий, направленных на гармонизацию межнациональных и межконфессиональных отношений на территории города Новосибирска, на 2017-2020 годы : постановление мәрии г. Новосибирска от 26 декабря 2016 г № 5980. [Электронный ресурс]// Архив Новосибирской области. URL: http://novosib-gov.ru/doc/59519 (дата обращения: 01.05.2018).

Персидская, О. А. (2017а) Межэтнический конфликт в Новосибирске глазами экспертного сообщества // Россия - пространство диалога народов : материалы II Всероссийской научнопрактической конференции. Новосибирск : ИПЦ НГУ. 80 с. С. 45-46.

Персидская, О. А. (2017b) Этническая диаспора в городе: образ в глазах принимающего сообщества // Социальные и пространственные измерения современного мегаполиса : материалы IX социологических чтений памяти В. Б. Голофаста. СПб. : Книжное издательство «Норма». 344 c. C. $247-255$.

Персидская, О. А., Попков, Ю. В., Скалабан, И. А. (2016) Мигранты в межэтническом сообществе Новосибирска: специфика взаимной адаптации // Вестник НГУЭУ. № 3. С. 229-239.

Попков, Ю. В. (2017) Государственная национальная политика как фактор межэтнической интеграции российского общества // Siberian Socium. T. 1. № 1. С. 114-131.

Попков, Ю. В., Костюк, В. Г. (2017) Факторы интеграции и дезинтеграции межэтнического сообщества города Новосибирска в оценках экспертов // Сибирский философский журнал. № 4. C. 163-172.

Попков, Ю. В., Тюгашев, Е. А. (2017) Феномен города как межэтнического сообщества // ЭКО. № 10. С. 7-19.

Сорокин, П. А. (2000) Социальная и культурная динамика: Исследование изменений в больших системах искусства, этики, права и общественных отношений / пер. с англ. В. В. Сапова. СПб. : РХГИ. 1054 с.

Ушаков, А. В. (2013) Новосибирск многонациональный: межэтнические отношения и воспроизводство этничности. Новосибирск : ООО «Издательский дом “Манускрипт”». 200 с.

Этносоциальные процессы и этнонациональная политика в регионах Сибири (2015) / под ред. Ю. В. Попкова. Новосибирск : ИзА-во СО РАН. 273 с.

Madiukova, S. A., Persidskaia, O. A. (2017) Ethnic enclaves as a social and territorial phenomenon (based on the city of Novosibirsk) // Журнал Сибирского федерального университета. Серия: Гуманитарные науки. Т. 10. №7. С. 983-994.

Aата поступления: 30.05.2018 г.

\section{SOCIAL AND CULTURAL DETERMINANTS \\ OF ETHNONATIONAL POLICY (EXEMPLIFIED BY NOVOSIBIRSK) \\ O. A. PERSIDSKAYA}

Institute of Philosophy and LaW, Siberian Branch, Russian Academy of Sciences

The article analyses the interethnic situation and the state of interethnic relations in the city of Novosibirsk. The population of the city is shown as an interethnic community - an integral social and cultural object, whose elements (ethnic groups) are simultaneously integrated into the community, but retain their ethnocultural distinctiveness. The aim of the article is to highlight a complex of social and cultural determinants - the factors of ethnosocial life that are significant for the community and set the direction for the development of the interethnic community. It is noted that, as these determinants have a significant influence on the harmony of the interethnic relations within the city space, their identification and analysis are of particular importance for ethnonational policy at the municipal level.

The author analysed the results of an expert poll conducted in Novosibirsk in 2016-2017. Social and cultural determinants imply, firstly, the complexities of social and economic nature, which deve- 
lop a sense of insecurity in the host community and reduce its level of tolerance to alien migrants. Secondly, the enclavement process that excludes places for the compact resettlement of migrants from the system of social and cultural exchange. Thirdly, the limited effectiveness of the measures taken by the administrative structures of the city to establish communication between the host population and the diasporas was considered to be the determinant that caused a number of problems in the field of interethnic relations.

The coducted analysis made it possible to conclude that, in order to harmonise interethnic relations in the city, it is necessary to raise the overall level of the population's well-being, monitor changes in the ethno-territorial structure of the city and seek fundamentally new mechanisms for communication between the host population and migrants. It is emphasised that, in order to increase its effectiveness, the municipal ethnonational policy should consider the inter-ethnic community as a whole to be its object, and take into account a wide range of social and cultural determinants influencing its development.

Keywords: social and cultural determinants; interethnic community; municipal ethnonational policy; Novosibirsk; migration; enclavement process; diaspora; social well-being

\section{REFERENCES}

Abramova, M. A., Goncharova, G. S. and Kostyuk, V. G. (2017) Osnovnye faktory integracii mezhehtnicheskih soobshchestv Rossii. Sibirskii filosofskii zhurnal, vol. 15, no. 1, pp. 149-158. (In Russ.).

Abramova, M. A., Kostyuk, V. G. (2018) Sociokul'turnye determinanty razvitiya i transformacii obshchestva i soobshchestv Rossii: issledovatel'skie podhody. Sibirskii filosofskii zburnal, no. 2, pp. 86-95. (In Russ.).

Antropov, E. V. (2013) Novosibirsk: ebtnicheskie aspekty vozniknoveniya i razvitiya goroda (konec XIX-nacbalo XXI v.) : Thesis of the Diss. ... Candidate of History. Tomsk. 17 p. (In Russ.).

Volkov, S. G. (2004) Determinizm v sociokul' turnom razvitii (filosofsko-metodologicheskijanaliz): Thesis of the Diss. ... Candidate of Philosophy. Tula. 19 p. (In Russ.).

Koncepciya realizacii nacional'noj politiki v gorode Novosibirske. Upravlenie obshchestvennykb sviazei merii Novosibirska [online] Avaliable at: http://www.uos.novo-sibirsk.ru/assets/files/documents/municipal/koncepciya-nac-polit.pdf (access date: 01.05.2018). (In Russ.).

Kostyuk, V. G. and Persidskaya, O. A. (2007) Novosibirskaya shkola ehtnosociologii: ehtapy stanovleniya, osnovnye rezul'taty. Gumanitarnye nauki v Sibiri, no. 1, pp. 14-18. (In Russ.).

Marhinin, V. V. and Udalova, I. V. (2014) Mezhehtnicheskoe soobshchestvo kak sociokul'turnyj koncept (postanovka problemy). Vestnik Novosibirskogo gosudarstvennogo universitetata. Seriya: Filosofiya, vol. 12, no. 1, pp. 70-78. (In Russ.).

O kompleksnom plane meropriyatij, napravlennyh na garmonizaciyu mezhnacional'nyh i mezhkonfessional'nyh otnoshenij na territorii goroda Novosibirska, na 2017-2020 gody. Arkbiv Novosibirskoi oblasti [online] Avaliable at: http://novosib-gov.ru/doc/59519 (access date: 01.05.2018). (In Russ.).

Persidskaya, O. A. (2017a) Mezhehtnicheskij konflikt v Novosibirske glazami ehkspertnogo soobshchestv. In: Rossiya - prostranstvo dialoga narodov. Materials of the II All-Russian Scientific and Practical Conference. Novosibirsk, NSU Publ. 80 p. Pp. 45-46.

Persidskaya, O. A. (2017b) Etnicheskaya diaspora v gorode: obraz v glazah prinimayushchego soobshchestva. In: Social' nye $i$ prostranstvennye izmereniya sovremennogo megapolisa. Materials of IX sociological readings in memory of V. B. Holofast. St. Petersburg, Norma Publ. 344 p. Pp. 247-255. (In Russ.).

Persidskaya, O. A., Popkov, Yu. V. and Skalaban, I. A. (2016) Migranty v mezhehtnicheskom soobshchestve Novosibirska: specifika vzaimnoj adaptacii. Vestnik NSUEU, no. 3, pp. 229-239. (In Russ.).

Popkov, Yu. V. (2017) Gosudarstvennaya nacional'naya politika kak faktor mezhehtnicheskoi integracii rossijskogo obshchestva. Siberian Socium, vol. 1, no. 1, pp. 114-131. (In Russ.). 
Popkov, Yu. V. and Kostyuk, V. G. (2017) Faktory integracii i dezintegracii mezhehtnicheskogo soobshchestva goroda Novosibirska v ocenkah ehkspertov. Sibirskij filosofskij zhurnal, no. 4, pp. 163-172. (In Russ.).

Popkov, Yu. V. and Tyugashev, E. A. (2017) Fenomen goroda kak mezhehtnicheskogo soobshchestva. EKO, no. 10, pp. 7-19. (In Russ.).

Sorokin, P. A. (2000) Social'naya i kul'turnaya dinamika: Issledovanie izmenenij v bol'shib sistemab iskusstva, ebtiki, prava i obshchestvennyb otnosbenij. St. Petersburg. RCHI Publ. 1054 p. (In Russ.).

Ushakov, D. V. (2013) Novosibirsk mnogonacional'nyj: mezhebtnicheskie otnosheniya i vosproizvodstvo ehtnichnosti. Novosibirsk, Manuskript Publ. 200 p. (In Russ.).

Etnosocial'nye processy $i$ ebtnonacional' naya politika $v$ regionab Sibiri (2015). Novosibirsk. SB RAS Publ. 273 p. (In Russ.).

Madiukova, S. A. and Persidskaia, O. A. (2017) Ethnic enclaves as a social and territorial phenomenon (based on the city of Novosibirsk). Zhurnal Sibirskogo federal' nogo universiteta. Seriya: Gumanitarnye nauki, vol. 10, no. 7, pp. 983-994.

Submission date: 30.05 .2018$.

Персидская Ольга Алексеевна - младший научный сотрудник отдела социальных и правовых исследований Института философии и права Сибирского отделения Российской академии наук. Адрес: 630090, г. Новосибирск, ул. Николаева, 8, каб. 408. Тел.: +7 (983) 123-37-90. Эл. aspec: olga_alekseevna@mail.ru

Persidskaya Olga Alekseyevna, Junior Research Fellow, Department of Social and Legal Studies, Institute of Philosophy and Law, Siberian Branch, Russian Academy of Sciences. Postal address: 8, Nikolayeva St., Novosibirsk, Russian Federation, 630090. Tel.: +7 (983) 123-37-90. E-mail: olga_ alekseevna@mail.ru 